\title{
A Randomized Trial Comparing 3- versus 4-Monthly Cardiac Monitoring in Patients Receiving Trastuzumab-Based Chemotherapy for Early Breast Cancer
}

\author{
Susan Dent 1,2, $+\ddagger$, Dean Fergusson ${ }^{3,+}$, Olexiy Aseyev ${ }^{4}$, Carol Stober ${ }^{2}$, Gregory Pond ${ }^{5}$, Arif A. Awan ${ }^{1}$, \\ Sharon F. McGee ${ }^{1}$, Terry L. $\mathrm{Ng}^{1}$, Demetrios Simos ${ }^{6}$, Lisa Vandermeer ${ }^{2}$, Deanna Saunders ${ }^{2}$, John F. Hilton ${ }^{1,2}$, \\ Brian Hutton ${ }^{3}$ and Mark Clemons ${ }^{1,2, *, \S} \mathbb{D}$ on behalf of the REaCT Investigators
}

check for updates

Citation: Dent, S.; Fergusson, D.; Aseyev, O.; Stober, C.; Pond, G.; Awan, A.A.; McGee, S.F.; Ng, T.L.; Simos, D.; Vandermeer, L.; et al. A Randomized Trial Comparing 3versus 4-Monthly Cardiac Monitoring in Patients Receiving TrastuzumabBased Chemotherapy for Early Breast Cancer. Curr. Oncol. 2021, 28, 5073-5083. https://doi.org/10.3390/ curroncol28060427

Received: 3 November 2021

Accepted: 28 November 2021

Published: 3 December 2021

Publisher's Note: MDPI stays neutral with regard to jurisdictional claims in published maps and institutional affiliations.

Copyright: (c) 2021 by the authors. Licensee MDPI, Basel, Switzerland. This article is an open access article distributed under the terms and conditions of the Creative Commons Attribution (CC BY) license (https:// creativecommons.org/licenses/by/ $4.0 /)$.
1 Division of Medical Oncology, Department of Medicine, The Ottawa Hospital, The University of Ottawa, Ottawa, ON K1H 8L6, Canada; susan.dent@duke.edu (S.D.); aawan@ohri.ca (A.A.A.); shmcgee@toh.ca (S.F.M.); teng@toh.ca (T.L.N.); jfhilton@toh.ca (J.F.H.)

2 Cancer Therapeutics Program, The Ottawa Hospital Research Institute, Ottawa, ON K1H 8L6, Canada; cstober@ohri.ca (C.S.); lvandermeer@ohri.ca (L.V.); dsaunders@ohri.ca (D.S.)

3 Clinical Epidemiology Program, The Ottawa Hospital Research Institute, The University of Ottawa, Ottawa, ON K1H 8L6, Canada; dafergusson@ohri.ca (D.F.); bhutton@ohri.ca (B.H.)

4 Thunder Bay Regional Cancer Care Northwest, Thunder Bay Regional Health Sciences Centre, Thunder Bay, ON P7B 6V4, Canada; aseyevo@tbh.net

5 Department of Oncology, McMaster University, Hamilton, ON L8S 4L8, Canada; gpond@mcmaster.ca

6 Stronach Regional Cancer Center, Southlake Regional Health Care Centre, Newmarket, ON L3Y 2P9, Canada; dsimos@southlakeregional.org

* Correspondence: mclemons@toh.ca; Tel.: +1-613-737-7700 (ext. 70170)

+ Denotes co-primary authors.

$\ddagger$ Current address: Duke Cancer Institute, Duke University, Durham, NC 27708, USA.

$\S \quad \mathrm{REaCT}$ Investigators are listed in acknowledgments.

Abstract: Purpose: The optimal frequency for cardiac monitoring of left ventricular ejection fraction (LVEF) in patients receiving trastuzumab-based therapy for early breast cancer (EBC) is unknown. We conducted a randomized controlled trial comparing 3-versus 4-monthly cardiac monitoring. Patients and Method: Patients scheduled to receive trastuzumab-containing cancer therapy for EBC with normal ( $>53 \%$ ) baseline LVEF were randomized to undergo LVEF assessments every 3 or 4 months. The primary outcome was the change in LVEF from baseline. Secondary outcomes included the rate of cardiac dysfunction (defined as a decrease in the LVEF of $\geq 10$ percentage points, to a value $<53 \%$ ), delays in or discontinuation of trastuzumab therapy, and cardiology referral. Results: Of the 200 eligible and enrolled patients, 100 (50\%) were randomized to 3-monthly and 100 (50\%) to 4-monthly cardiac monitoring. Of these patients, 98 and 97 respectively underwent at least one cardiac scan. The estimated mean difference in LVEF from baseline was $-0.94 \%$ (one-sided $95 \%$ lower bound: -2.14 ), which exceeded the pre-defined non-inferiority margin of $-4 \%$. There were also no significant differences between the two study arms for any of the secondary endpoints. The rate of detection of cardiac dysfunction was 16.3\% (16/98) and 12.4\% (12/97) in the 3- and 4-monthly arms, respectively $(95 \%$ CI: $4.0[-5.9,13.8])$. Conclusions: Cardiac monitoring every 4 months was deemed non-inferior to that every 3 months in patients with HER2-positive EBC being treated with trastuzumab-based therapy. Given its costs and inconvenience, cardiac monitoring every 4 months should be considered standard practice. Registration: NCT02696707, 18 February 2016.

Keywords: trastuzumab; breast cancer; cardiac monitoring

\section{Introduction}

Despite the extensive global use of trastuzumab, there is minimal high-quality evidence on the optimal schedule of routine cardiac monitoring [1,2]. While well-intentioned, the high frequency of cardiac monitoring (baseline, every 3 months during treatment) 
recommended by the FDA in patients receiving trastuzumab-based therapy has led to increased detection of asymptomatic drops in LVEF [3], the clinical significance of which is unknown. Detection of early (asymptomatic) cardiotoxicity places patients at risk of not completing their intended HER2-targeted therapy, thus increasing the risk of cancer recurrence and death in the adjuvant setting [4]. Current position statements/guideline statements recommend LVEF evaluation every 3 [1,2,5-7] or 4 [8] months during trastuzumabbased therapy; however, healthcare providers are now questioning the value of cardiac monitoring in patients at low risk of cardiotoxicity-especially in the context of the global COVID-19 pandemic $[9,10]$.

In view of this variability in practice, the current study was designed to compare two standards of care schedules (3- versus 4-monthly imaging) for cardiac monitoring of patients receiving trastuzumab-based chemotherapy for EBC. It was hypothesized that cardiac monitoring (echocardiogram/MUGA) every 4 months would not be inferior to monitoring every 3 months for the detection of changes in LVEF, and as a result, there would be no difference in the rate of detection of cardiac dysfunction.

\section{Patients and Methods}

Eligible patients with histologically confirmed HER2-positive EBC (stages I-III), with no prior history of chemotherapy, and who were scheduled to receive one year of neo/adjuvant trastuzumab-containing cancer therapy were approached for study participation by their treating oncologist at three cancer centers in Ontario, Canada. Patients had to be able to provide verbal consent through the integrated consent model [11] and have a normal LVEF ( $>53 \%$ ) prior to initiation of trastuzumab therapy. Patients with a contraindication to receiving trastuzumab were excluded. Regulatory approval for this study was granted by the research ethics board at each participating center (OHSN-REB 20150777-01H).

\subsection{Randomization}

This study was a multi-center, two-arm, open-label, randomized non-inferiority trial. Eligible and consented patients were randomized 1:1 to either 3- or 4-monthly cardiac monitoring during trastuzumab-based therapy. While the choice of imaging modality (i.e., echocardiogram or MUGA) was at the discretion of the provider, physicians were requested to use the same imaging modality throughout the study. Assignment to treatment groups was stratified by center and chemotherapy backbone (anthracycline- vs. non-anthracyclinebased). Randomization was performed using a permuted block design of variable block sizes of 4 and 6 developed by The Ottawa Methods Centre.

\subsection{Procedures}

Trastuzumab (Herceptin ${ }^{\circledR}$; Genentech, San Francisco, CA, USA) dose and dosing interval were as per the standard of care. Follow-up visits during chemotherapy and trastuzumab occurred as per usual care as the study did not mandate visit schedules. Physicians could order additional cardiac evaluations if they felt it was warranted.

\subsection{Outcomes}

The primary objective was to demonstrate that cardiac monitoring (echocardiogram/MUGA) every 4 months was not inferior to that every 3 months in detecting rates of cardiac dysfunction. To evaluate this, the primary endpoint was change in LVEF throughout the course of trastuzumab-based therapy. Secondary endpoints included the frequency of detection of cardiac dysfunction (defined as a decrease of $\geq 10 \%$ in LVEF to below a threshold of 53\% [12,13] as measured by echocardiography or MUGA), rates of delay or discontinuation of trastuzumab therapy, and referrals to cardiology. Cardiac adverse events were collected and defined according to the Common Terminology Criteria for Adverse Events (CTCAE) version 4.0 as well as study-specific questions on cardiac-related emergency room visits and hospitalizations, referral to cardiology, and changes in cardiac 
medications. Information on comorbidities (e.g., CAD/stroke/peripheral vascular disease, smoking, atrial fibrillation, obesity, hypertension, dyslipidemia, and diabetes) was collected at baseline for all patients. Outcome data were collected from case report forms completed by the physician when the patient was seen in clinic and after each cardiac evaluation as well as from the patient's electronic health records.

A protocol amendment was made on 29 January 2018 to add the collection of health system utilization data using the EQ-5D-5L questionnaire [14] as well as cardiac medication and emergency room visits at baseline, following the first cardiac monitoring scan (i.e., after month 3 or 4 ) and at the end of the follow-up.

\subsection{Sample Size Calculation}

The sample size calculation was based on a normal LVEF $>53 \%$ (mean is $61 \%$ with standard deviation of $8 \%$ ). In adjuvant clinical trials, the majority of patients during trastuzumab treatment experienced a reversible decrease in LVEF of between 4 and $6 \%$. The non-inferiority margin between groups was set as $4 \%\left(\mathrm{MLVEF}_{3 \mathrm{~m}}-\mathrm{MLVEF}_{4 \mathrm{~m}}< \pm 4 \%\right)$ using a one-sided $95 \%$ confidence interval. Based on these considerations, a sample size of 87 patients in each group was required. To account for potential drop-out, the sample size was increased by approximately $10 \%$, and recruitment of 200 participants was targeted.

\subsection{Statistical Considerations}

\subsubsection{Per Protocol Analysis}

As we were assessing non-inferiority, the primary analysis was based on the per protocol population, which is a more conservative approach. The per protocol population (PP) consisted of all patients who consented to treatment, met all the eligibility requirements, were randomized to a treatment, and had their first cardiac scan as per the assigned allocation. If the cardiac scanning frequency changed after the initial cardiac scan, patients were still assessed in the per protocol population; however, the reasons for the change in scanning frequency were determined.

\subsubsection{Intention-to-Treat Analysis}

A supportive analysis was performed using the ITT population, which consisted of all patients who consented to treatment, met all the eligibility requirements, and were randomized to a treatment. Additionally, secondary analyses were based on the ITT population. Patients who underwent cardiac scanning at a frequency which differed from that to which they were initially allocated were considered part of the ITT population.

\subsubsection{General Statistical Considerations}

Baseline characteristics are presented using descriptive statistics. Outcomes of interest were estimated with two-sided confidence intervals, and statistical significance was defined at the $\alpha=0.05$ level.

\subsubsection{Analysis of the Primary Outcome (LVEF)}

The primary outcome (LVEF) was measured at baseline and every 3 or 4 months, with the primary (and common) time point measure at 1 year. A repeated measures analysis was used to estimate the expected change in treatment effect and confidence interval, i.e., whether or not the 4-monthly group was found to be inferior by a margin of $4 \%$. If the lower bound of the $95 \%$ one-sided confidence interval included the non-inferiority margin, the 4-monthly regimen would be deemed non-inferior to the 3-monthly regimen. As a supportive analysis, the mean difference between both treatment groups at one year of follow-up and the last measured LVEF while on trastuzumab treatment was assessed and summarized. 


\subsubsection{Subgroup Analyses}

Differences between subgroups were explored for the following a priori selected subgroups: treatment center and use of anthracycline- versus non-anthracycline-based chemotherapy.

\section{Results}

\subsection{Patients}

Between 6 June 2016 and 30 April 2019, 200 patients were enrolled (CONSORT diagram, Figure 1).

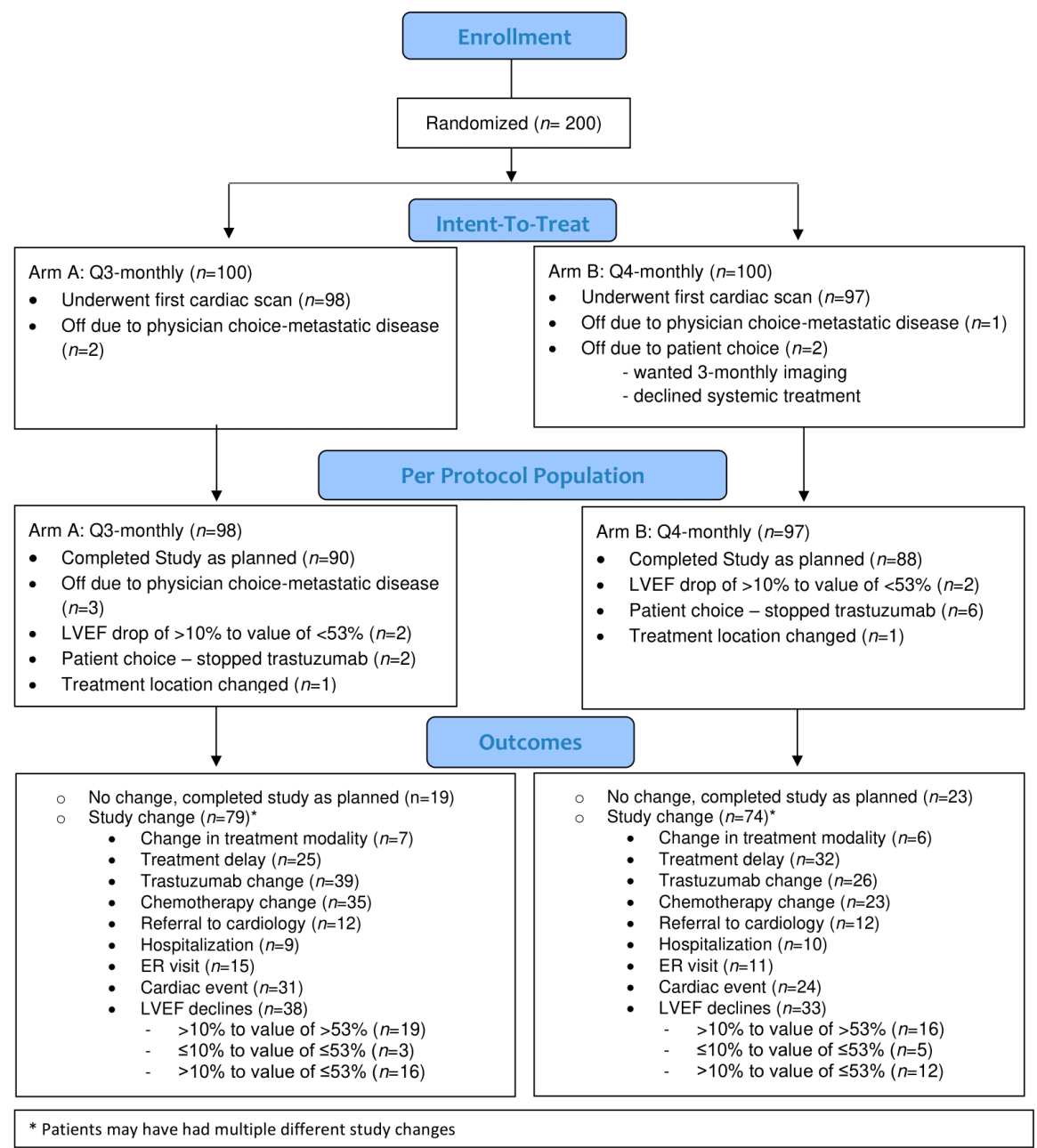

Figure 1. CONSORT flow diagram.

Of these eligible and consented patients, $100(50 \%)$ were randomized to 3-monthly cardiac monitoring and $100(50 \%)$ to 4-monthly imaging. The baseline characteristics of the per protocol (PP) population (i.e., all patients who consented to treatment, met all eligibility requirements, were randomized to treatment, and had their first cardiac scan as per the assigned allocation) and the intention-to-treat (ITT) population (i.e., all patients who consented to treatment, met all eligibility requirements, and were randomized) are presented in Table 1 and Supplemental Table S1, respectively. 
Table 1. Characteristics (per protocol population).

\begin{tabular}{|c|c|c|}
\hline & Q3-Monthly & Q4-Monthly \\
\hline$N$ & 98 & 97 \\
\hline \multicolumn{3}{|l|}{ Patient Characteristics } \\
\hline \multicolumn{3}{|l|}{ Age } \\
\hline Median [IQR] range & $55.7[47.0-62.0] 32-83$ & $56.0[47.3-62.1] 28-77$ \\
\hline Mean (SD) & $55.4(11.4)$ & $54.8(11.3)$ \\
\hline \multicolumn{3}{|l|}{ Baseline LVEF } \\
\hline Median (IQR) range & $65[60-68] 54-82$ & $64[61-67] 54-76$ \\
\hline Mean (SD) & $64.5(5.4)$ & $64.0(5.0)$ \\
\hline Baseline modality, $N(\%)$ echocardiogram & $71(72.5)$ & $69(71.1)$ \\
\hline $\mathrm{CV}$ risk factors, $N(\%)$ Yes & $49(50.0)$ & $51(52.6)$ \\
\hline CAD stroke PVD, $N(\%)$ Yes & $1(1.0)$ & $0(0.0)$ \\
\hline Atrial fibrillation, $N(\%)$ Yes & $1(1.0)$ & $2(2.1)$ \\
\hline Obesity, N (\%) Yes & $10(10.2)$ & $15(15.5)$ \\
\hline \multicolumn{3}{|l|}{ Smoking status } \\
\hline Non-smoker, $N(\%)$ & $81(82.7)$ & $79(81.4)$ \\
\hline Current smoker & $5(5.1)$ & $5(5.2)$ \\
\hline Past smoker & $12(12.2)$ & $13(13.4)$ \\
\hline Hypertension, $N(\%)$ Yes & $21(21.4)$ & $19(19.6)$ \\
\hline Diabetes, $N(\%)$ Yes & $9(9.2)$ & $3(3.1)$ \\
\hline Angina, $N(\%)$ Yes & $1(1.0)$ & $0(0.0)$ \\
\hline Dyslipidemia, $N(\%)$ Yes & $12(12.2)$ & $7(7.2)$ \\
\hline Other risk factors * $N(\%)$ Yes & $5(5.1)$ & $6(6.2)$ \\
\hline \multicolumn{3}{|l|}{ Treatments } \\
\hline \multicolumn{3}{|l|}{ Chemotherapy type } \\
\hline$N(\%)$ Anthracycline-based & $53(54.1)$ & $50(51.6)$ \\
\hline \multicolumn{3}{|l|}{ Radiation On-Study } \\
\hline$N(\%)$ Yes & $79(80.6)$ & $68(70.1)$ \\
\hline Median (range) dose & $50(40-92.6)$ & $50(40-87.1)$ \\
\hline$N(\%)$ Location: Left & $45(57.0)$ & $35(51.5)$ \\
\hline left & $34(43.0)$ & $32(47.1)$ \\
\hline Both & $0(0.0)$ & $1(1.5)$ \\
\hline $\begin{array}{l}\text { Medication information (available in } \\
\text { only } n=83 \text { patients) }\end{array}$ & 39 & 43 \\
\hline Medication, $N(\%)$ Yes & $6(15.4)$ & $10(23.3)$ \\
\hline Aspirin, $N(\%)$ Yes & $0(0.0)$ & $1(2.3)$ \\
\hline ACE-inhibitor, $N(\%)$ Yes & $3(7.7)$ & $7(16.3)$ \\
\hline Beta blocker, $N(\%)$ Yes & $3(7.7)$ & $0(0.0)$ \\
\hline Angiotensin blocker, $N(\%)$ Yes & $1(2.6)$ & $3(7.0)$ \\
\hline CA channel antagonist, $N(\%)$ Yes & $3(7.7)$ & $0(0.0)$ \\
\hline Diuretic, $N(\%)$ Yes & $2(5.1)$ & $3(7.0)$ \\
\hline Statin, $N(\%)$ Yes & $1(2.6)$ & $1(2.3)$ \\
\hline Other medications, $N(\%)$ Yes & $0(0.0)$ & $1(2.3)$ \\
\hline \multicolumn{3}{|l|}{ Outcomes } \\
\hline \multicolumn{3}{|l|}{ Completed study as planned } \\
\hline$N(\%)$ Yes & $90(91.8)$ & $88(90.7)$ \\
\hline Reason $=\mathrm{LVEF}$ & 2 & 2 \\
\hline Stopped trastuzumab & 2 & 6 \\
\hline Metastatic disease & 3 & 0 \\
\hline Location changed & 1 & 1 \\
\hline
\end{tabular}

For the PP population, the median age of patients in the 3- and 4-monthly arms was 55.7 years [IQR 47.0-62.0] and 56.0 years [IQR 47.3-62.1], respectively. Baseline LVEF 
(medians: 65\% [IQR 60-68] vs. 64\% [IQR 61-67]) and use of echocardiogram for cardiac monitoring $(72.5 \%$ vs. $71.1 \%)$ were well balanced in both the 3- and 4-monthly arms (Table 2). The patient population was generally healthy, with 49 patients $(50.0 \%)$ in the 3 -month arm and 51 (52.6\%) in the 4-month arm having baseline cardiovascular risk factors. In addition, anthracycline-based chemotherapy was received by a total of $53(54.1 \%)$ and $50(51.6 \%)$ patients in the 3- and 4-monthly arms, respectively. Use of cardiac medications was only collected after the protocol amendment and was well matched in the two study arms (Table 2). At the time of analysis, the median follow-up duration was 365 days for patients in both arms.

Table 2. Outcomes (per protocol population).

\begin{tabular}{|c|c|c|c|c|}
\hline & & Q3-Monthly & Q4-Monthly & Diff $(95 \%$ CI) \\
\hline$N$ & & 98 & 97 & \\
\hline \multicolumn{5}{|l|}{ Primary Outcome } \\
\hline $\begin{array}{l}\text { Any change in LVEF from } \\
\text { baseline }\end{array}$ & $N(\%)$ Yes & 79 (80.6) & $74(76.3)$ & $4.3(-7.2,15.9)$ \\
\hline Absolute change in LVEF & $\begin{array}{l}\text { Median [IQR] range } \\
\text { Mean (SD) }\end{array}$ & $\begin{array}{c}-8[-1,-4]-26 \text { to } 17 \\
-7.4(6.5)\end{array}$ & $\begin{array}{c}-6[-10,-2]-33 \text { to } 10 \\
-6.8(6.8)\end{array}$ & $-0.6[-2.5,1.2]$ \\
\hline \multicolumn{5}{|l|}{ Secondary Outcomes } \\
\hline \multirow{4}{*}{ Change in LVEF } & No decline & $60(61.2)$ & $64(66.0)$ & \\
\hline & $\begin{array}{c}\text { Decline }>10 \% \text { to value } \\
\text { of }>53 \%\end{array}$ & $19(19.4)$ & $16(16.5)$ & \\
\hline & $\begin{array}{c}\text { Decline } \leq 10 \% \text { to value } \\
\text { of } \leq 53 \%\end{array}$ & $3(3.1)$ & $5(5.2)$ & \\
\hline & $\begin{array}{c}\text { Decline }>10 \% \text { to value } \\
\text { of } \leq 53 \%\end{array}$ & $16(16.3)$ & $12(12.4)$ & \\
\hline Cardiac dysfunction & $N(\%)$ Yes & $16(16.3)$ & $12(12.4)$ & $4.0(-5.9,13.8)$ \\
\hline Cardiac event & \multirow{4}{*}{$N(\%)$ Yes } & $31(31.6)$ & $24(24.7)$ & \multirow{4}{*}{$6.9(-5.7,19.5)$} \\
\hline Decrease in EF & & $6(66.7)$ & $10(90.9)$ & \\
\hline Congestive heart failure & & $1(11.1)$ & 0() & \\
\hline Other* & & $2(22.2)$ & $1(9.1)$ & \\
\hline $\begin{array}{l}\text { Change in type of } \\
\text { imaging modality }\end{array}$ & $N(\%)$ Yes & $7(7.1)$ & $6(6.2)$ & $1.0(-6.0,8.0)$ \\
\hline Trastuzumab & \multirow{4}{*}{$N(\%)$ Yes } & $14(14.3)$ & $10(10.3)$ & $4.0(-5.2,13.2)$ \\
\hline Delays & & $9(9.2)$ & $2(2.1)$ & $7.1(0.7,13.5)$ \\
\hline Reduction & & $3(3.1)$ & $1(1.0)$ & $2.0(-1.9,6.0)$ \\
\hline Discontinuation ** & & $2(2.0)$ & $7(7.2)$ & $-5.2(-11.0,0.7)$ \\
\hline Chemotherapy & \multirow{4}{*}{$N(\%)$ Yes } & $35(35.7)$ & $23(23.7)$ & 12. $0(-0.7,24.7)$ \\
\hline Delay & & $7(7.1)$ & $9(9.3)$ & $-2.1(-9.8,5.6)$ \\
\hline Reduction & & $12(12.2)$ & $6(6.2)$ & $6.1(-2.0,14.1)$ \\
\hline Discontinuation & & $16(16.3)$ & $8(8.3)$ & $8.1(-1.1,17.2)$ \\
\hline Referral to cardiology & $N(\%)$ Yes & $12(12.2)$ & $12(12.4)$ & $-0.1(-9.4,9.1)$ \\
\hline $\begin{array}{l}\text { Treatment-related } \\
\text { hospitalization } * * *\end{array}$ & $N(\%)$ Yes & $9(9.2)$ & $10(10.3)$ & $-1.1(-9.5,7.2)$ \\
\hline $\begin{array}{l}\text { Treatment-related ER } \\
\text { visit****}\end{array}$ & $N(\%)$ Yes & $15(15.3)$ & $11(11.3)$ & $4.0(-5.6,13.5)$ \\
\hline
\end{tabular}

* Other refers to change in blood pressure, chest pain/shortness of breath, or irregular heartbeat. ${ }^{* *}$ Reasons included decrease in EF, patient choice, timing around breast surgery for neoadjuvant patients, ER visit, or a hospitalization. ${ }^{* * *}$ There were no cardiac-related hospitalizations. ${ }^{* * * *}$ There was one cardiac-related ER visit due to shortness of breath but ECG was normal. 


\subsection{Primary Outcome}

The median absolute change in LVEF was - $8 \%$ [IQR -1, -4] in the 3-monthly arm and $-6 \%$ [IQR $-10,-2]$ in the 4-monthly arm $(95 \% \mathrm{CI}$ for the mean change between interventions: -0.6 [IQR $-2.5,1.2]$ ) (Table 2). The mean values of LVEF over the study period are shown in Table 3. By the end of week 48, the mean (standard deviation (SD)) LVEF was 60.7 (6.2) for patients in the Q3-montly arm and 60.3 (7.0) for patients in the Q4monthly arm. This translates to a mean (SD) change in baseline of $-7.5 \%(6.2 \%)$ and $-6.8 \%$ (6.9) for the Q3- and Q4-monthly arms, respectively. The results of the repeated measures analysis are in Supplemental Table S2 and show no interaction effect. The estimated mean difference in LVEF for patients on trastuzumab was $-0.94 \%$ (one-sided $95 \%$ lower bound: $-2.14)$, which exceeded the pre-defined non-inferiority margin of $-4 \%$.

Table 3. Mean (SD) LVEF over time.

\begin{tabular}{|c|c|c|c|}
\hline Time Period & $N$ & Q3-Monthly & Q4-Monthly \\
\hline Week 12 & 97 & $61.2(5.9)$ & \\
\hline Week 16 & 95 & & $61.0(5.2)$ \\
\hline Week 24 & 97 & $59.7(5.7)$ & \\
\hline Week 32 & 94 & & $61.2(6.1)$ \\
\hline Week 36 & 95 & $60.6(6.2)$ & \\
\hline Week 48 & $93 / 93$ & $60.7(6.2)$ & $60.3(7.0)$ \\
\hline \multicolumn{2}{|c|}{ Mean $(95 \% \mathrm{CI})$ difference at week 48} & \multicolumn{2}{|c|}{$0.40(-1.48,2.34)$} \\
\hline \multicolumn{4}{|c|}{ Change in LVEF from baseline } \\
\hline Week 12 & 97 & $-3.3(6.2)$ & \\
\hline Week 16 & 95 & & $-2.9(5.3)$ \\
\hline Week 24 & 97 & $-6.0(6.4)$ & \\
\hline Week 32 & 94 & & $-5.0(5.8)$ \\
\hline Week 36 & 95 & $-6.9(6.3)$ & \\
\hline Week 48 & $93 / 93$ & $-7.5(6.2)$ & $-6.8(6.9)$ \\
\hline \multicolumn{2}{|c|}{ Mean $(95 \% \mathrm{CI})$ difference at week 48} & \multicolumn{2}{|c|}{$-0.69(-2.59,1.21)$} \\
\hline
\end{tabular}

\subsection{Secondary Outcomes}

Findings regarding the secondary outcomes are presented in Table 2. Any change in LVEF from baseline at any time during the study period was reported in a total of $79(80.6 \%)$ and $74(76.3 \%)$ patients in the 3- and 4-monthly arms, respectively (95\% CI: $4.3(-7.2,15.9)$ ). The variables used in the definition of cardiac dysfunction (i.e., decrease in LVEF of $\geq 10 \%$, to a threshold of $<53 \%$ ) and the rate of cardiac dysfunction are shown in Table 2 . The rate of detection of cardiac dysfunction was $16.3 \%(16 / 98)$ and $12.4 \%(12 / 97)$ in the 3 - and 4-monthly cardiac monitoring arms, respectively (two-sided 95\% CI: $4.0(-5.9,13.8)$ ).

A similar number of patients experienced changes in trastuzumab administration in the 3-monthly and 4-monthly arms (14.3\% vs. $10.3 \%$, respectively), with a difference of $4.0 \%(95 \% \mathrm{CI}=-5.2$ to $13.2 \%)$. Similarly, $35(35.7 \%)$ and $23(23.7 \%)$ patients, respectively, had a change in chemotherapy $(12.0 \%, 95 \% \mathrm{CI}=-0.7$ to $24.7 \%)$. The rates of referral to cardiology ( $12.2 \%$ vs. $12.4 \%$ ), incidence of grade heart failure (one patient vs. none), and cardiac-related emergency room visits (one patient vs. none) were similar in the study arms (Table 2).

No interaction effect was observed based on site of recruitment ( $p$-value $=0.18)$ or prior anthracycline use $(p$-value $=0.15)$ with the intervention arm. No effect due to site $(p$-value $=0.53)$ was observed. The mean decrease in LVEF from baseline was greater amongst patients receiving anthracycline-based chemotherapy (mean $-6.5 \%, \mathrm{SD}=6.3 \%$, 
across all time points) compared to non-anthracycline-based chemotherapy (mean $-4.4 \%$, $\mathrm{SD}=6.4 \%$; estimate $=-1.52 ; 95 \% \mathrm{CI}=-2.52$ to -0.52$)$ in the repeated measures model.

\section{Discussion}

Despite the widespread adoption of trastuzumab-based cancer therapies in the treatment of early stage HER2+ breast cancer, the optimal frequency of cardiac imaging is unknown, with most guidelines recommending either 3- or 4-monthly cardiac imaging [6,8,15]. This variability is in part driven by local resources and patient access and compliance as well as differences in the type of imaging test performed, including transthoracic echocardiography (echocardiogram) and multiple gated acquisition scan (MUGA); the chemotherapy backbone used; and the different endpoints used to define "significant cardiotoxicity" $[9,16]$. The current pragmatic trial permitted different cardiac imaging modalities with the use of any chemotherapy backbone. To our knowledge, there are no prospective clinical trials that have addressed the frequency of cardiac imaging for HER2-targeted therapies [4].

The current study confirmed that 4-monthly LVEF evaluation was not inferior to $3-$ monthly imaging. The reported incidence of cardiac dysfunction was $16.3 \%(16 / 98)$ and $12.4 \%(12 / 97)$ in the 3- and 4-monthly arms, respectively (95\% CI: 4.0 [IQR - 5.9, 13.8]; $p$ $=0.69$ ), which is similar to that reported in other trials [4]. Comparison with other trials is challenging as other studies have evaluated different chemotherapy regimens [17-20], used various definitions of cardiac dysfunction [12,17,21-23], and used different imaging modalities (e.g., MUGA or echocardiograms) [24,25]. Similarly, there were no significant differences in the secondary outcomes including changes in LVEF, delays or discontinuation of trastuzumab therapy, or referral to cardiology.

Given the increasing cost and complexity of clinical trials, the REaCT program was designed to perform practical pragmatic trials. These trials have previously evaluated surgical treatment [26], adjuvant treatment [27], use of central lines [28], supportive care [29], and palliative care (interventions) [30], but this is the first trial evaluating whether the integrated consent model is feasible with regards to ordering routine imaging modalities. Feasibility of trial design and protocol uptake was assessed through physician engagement (defined as the percentage of medical oncologists who agreed to participate in the trial compared with physicians that actually approached patients regarding the trial). For each study site, physician engagement was as follows: Ottawa, 14/16 physicians; Southlake, 4/8 physicians; and Thunder Bay, 3/5 physicians, for an overall engagement of $72 \%(21 / 29)$.

As with all clinical trials, there are study limitations. Firstly, it has a relatively small sample size, being performed at three Canadian cancer centers. However, the use of broad inclusion criteria meant that the study population reflected real-world practice. At the time the study was performed, there was little concurrent use of pertuzumab and trastuzumab in Ontario. Like all studies, there may be limitations on the types of patients enrolled, with physicians tending to recruit mainly young, healthy patients. There is also the limitation of the imaging techniques as only either MUGAs or echocardiograms were allowed; however, this too reflects real-world practice. This limitation would also include the fact that we did not prospectively design the study to collect data on either strain values for the imaging techniques used or NHYA data on those referred for cardiology assessment.

Future trials should address whether changes towards non-anthracycline-based chemotherapy should alter cardiac monitoring strategies, as the majority of patients are younger, at low risk of cardiac complications, and may not require such frequent monitoring. Similarly, we need to identify a priori those patients who are at increased risk of cardiac-related treatment complications. Whether this should be through novel imaging techniques or biomarker measurement remains to be elucidated [4]. Another important factor that future studies should address includes optimizing the frequency and duration of cardiac imaging after completion of trastuzumab therapy, something the current study did not evaluate. 


\section{Conclusions}

Cardiac monitoring every 4 months was non-inferior to that every 3 months in early stage HER2-positive breast cancer patients being treated with trastuzumab-based therapy and should therefore be considered the standard of care.

Supplementary Materials: The following are available online at https:/ / www.mdpi.com/article / 10.3390/curroncol28060427/s1, Table S1: Baseline characteristics (intention-to-treat population); Table S2: Analysis of change in LVEF from baseline (per protocol population).

Author Contributions: Conceptualization, S.D., D.F., L.V., J.F.H., B.H., and M.C.; data curation, O.A., C.S., A.A.A., S.F.M., T.L.N., D.S. (Demetrios Simos), D.S. (Deanna Saunders), J.F.H., and M.C.; formal analysis, G.P.; funding acquisition, M.C.; investigation, S.D., C.S., A.A.A., D.S. (Deanna Saunders), J.F.H., and M.C.; methodology, S.D., D.F., G.P., and B.H.; project administration, C.S., L.V., D.S. (Deanna Saunders), and M.C.; resources, L.V.; supervision, J.F.H. and M.C.; writing-original draft, M.C.; writing—review and editing, S.D., D.F., O.A., C.S., G.P., A.A.A., S.F.M., T.L.N., D.S. (Demetrios Simos), L.V., D.S. (Deanna Saunders), J.F.H., B.H., and M.C. All authors have read and agreed to the published version of the manuscript.

Funding: This research did not receive any specific grant from funding agencies in the public, commercial, or not-for-profit sectors. This work was supported by the Rethinking Clinical Trials $(\mathrm{REaCT})$ program platform at the Ottawa Hospital, which is supported by The Ottawa Hospital Foundation and its donors.

Institutional Review Board Statement: This study was conducted according to the guidelines of the Declaration of Helsinki and was approved by the Ontario Health Science Network Research Ethics Board (OHSN-REB 20150777-01H), Southlake Regional Health Centre Research Ethics Board, and the Thunder Bay Regional Health Sciences Centre Research Ethics Board (TBRHSC REB).

Informed Consent Statement: Integrated oral consent was obtained from all subjects involved in the study.

Data Availability Statement: The data generated and/or analyzed during the current study are available from the corresponding author on request with approval from the Ottawa Health Science Network Research Ethics Board.

Acknowledgments: We are grateful for patients and their families for their assistance with this study, as well as physicians for approaching patients. Main accrual by physician was in the following order: Clemons (88), Dent (23), Aseyev (13), Awan (11), Segal (11), Verma (7), Ng (6), McGee (6), Simos (6), Hsu (5), Song (5), Chan (5), Hilton (4), Basulaiman (3), Sehdev (3), Zibdawi (2), Faghih (1), Goel (1), Kassam (1), Rahim (1). We are grateful to Moira Rushton-Marovac for editorial assistance. Funding was provided by the Ottawa REaCT Program with additional support from Cancer Care Ontario COQI grants (Government of Ontario).

Conflicts of Interest: G.P. reports personal fees (honoraria) from AstraZeneca and Merck outside of this work, as well as a family member who works for Roche and owns stock in Roche. T.N. has received honoraria from Takeda Oncology, ARIAD, and Boehringer-Ingelheim outside of this work. B.H. consults for Cornerstone Research and has received honoraria from Eversana Inc. for the provision of methodological advice related to the conduct of systematic reviews and meta-analysis. M.C. reports consulting fees from Cornerstone Research outside the submitted work. All other authors declare no competing interests.

\section{References}

1. Dang, C.T.; Anthony, F.Y.; Jones, L.W.; Liu, J.; Steingart, R.M.; Argolo, D.F.; Norton, L.; Hudis, C.A. Cardiac surveillance guidelines for trastuzumab-containing therapy in early-stage breast cancer: Getting to the heart of the matter. J. Clin. Oncol. 2016, 34, 1030-1033. [CrossRef] [PubMed]

2. Yu, A.; Yin, A.; Liu, J.; Steingart, R. Cost-effectiveness of cardiotoxicity monitoring. Am. Coll. Cardiol. Expert Anal. $2017,19,330$.

3. Mehta, L.S.; Watson, K.E.; Barac, A.; Beckie, T.M.; Bittner, V.; Cruz-Flores, S.; Dent, S.; Kondapalli, L.; Ky, B.; Okwuosa, T. Cardiovascular disease and breast cancer: Where these entities intersect: A scientific statement from the American Heart Association. Circulation 2018, 137, e30-e66. [CrossRef] [PubMed]

4. Rushton, M.; Lima, I.; Tuna, M.; Johnson, C.; Ivars, J.; Pritchard, K.; Hawken, S.; Dent, S. Impact of Stopping Trastuzumab in Early Breast Cancer: A Population-Based Study in Ontario, Canada. J. Natl. Cancer Inst. 2020, 112, 1222-1230. [CrossRef] [PubMed] 
5. Virani, S.A.; Dent, S.; Brezden-Masley, C.; Clarke, B.; Davis, M.K.; Jassal, D.S.; Johnson, C.; Lemieux, J.; Paterson, I.; Sebag, I.A. Canadian Cardiovascular Society guidelines for evaluation and management of cardiovascular complications of cancer therapy. Can. J. Cardiol. 2016, 32, 831-841. [CrossRef] [PubMed]

6. Curigliano, G.; Cardinale, D.; Suter, T.; Plataniotis, G.; De Azambuja, E.; Sandri, M.T.; Criscitiello, C.; Goldhirsch, A.; Cipolla, C.; Roila, F. Cardiovascular toxicity induced by chemotherapy, targeted agents and radiotherapy: ESMO Clinical Practice Guidelines. Ann. Oncol. 2012, 23, vii155-vii166. [CrossRef] [PubMed]

7. Armenian, S.H.; Lacchetti, C.; Barac, A.; Carver, J.; Constine, L.S.; Denduluri, N.; Dent, S.; Douglas, P.S.; Durand, J.-B.; Ewer, M. Prevention and monitoring of cardiac dysfunction in survivors of adult cancers: American Society of Clinical Oncology Clinical Practice Guideline. J. Clin. Oncol. 2017, 35, 893-911. [CrossRef]

8. Jones, A.; Barlow, M.; Barrett-Lee, P.; Canney, P.A.; Gilmour, I.; Robb, S.; Plummer, C.; Wardley, A.M.; Verrill, M.W. Management of cardiac health in trastuzumab-treated patients with breast cancer: Updated United Kingdom National Cancer Research Institute recommendations for monitoring. Br. J. Cancer 2009, 100, 684-692. [CrossRef]

9. Bouwer, N.I.; Jager, A.; Liesting, C.; Kofflard, M.J.; Brugts, J.J.; Kitzen, J.J.; Boersma, E.; Levin, M.-D. Cardiac monitoring in HER2-positive patients on trastuzumab treatment: A review and implications for clinical practice. Breast 2020, 52, 33-44. [CrossRef] [PubMed]

10. Surujballi, J.; Shah, H.; Hutton, B.; Alzahrani, M.; Beltran-Bless, A.-A.; Shorr, R.; Larocque, G.; McGee, S.; Cole, K.; Ibrahim, M.F.; et al. The COVID-19 pandemic: An opportunity to rethink and harmonise the frequency of follow-up visits for patients with early stage breast cancer. Cancer Treat. Rev. 2021, 97, 102188. [CrossRef] [PubMed]

11. Kim, S.Y.; Miller, F.G. Informed consent for pragmatic trials-the integrated consent model. N. Engl. J. Med. 2014, 370, 769-772. [CrossRef]

12. Plana, J.C.; Galderisi, M.; Barac, A.; Ewer, M.S.; Ky, B.; Scherrer-Crosbie, M.; Ganame, J.; Sebag, I.A.; Agler, D.A.; Badano, L.P. Expert consensus for multimodality imaging evaluation of adult patients during and after cancer therapy: A report from the American Society of Echocardiography and the European Association of Cardiovascular Imaging. Eur. Heart J.-Cardiovasc. Imaging 2014, 15, 1063-1093. [CrossRef]

13. Ponikowski, P.; Voors, A.A.; Anker, S.D.; Bueno, H.; Cleland, J.G.; Coats, A.J.; Falk, V.; González-Juanatey, J.R.; Harjola, V.-P.; Jankowska, E.A. 2016 ESC Guidelines for the diagnosis and treatment of acute and chronic heart failure: The Task Force for the diagnosis and treatment of acute and chronic heart failure of the European Society of Cardiology (ESC) Developed with the special contribution of the Heart Failure Association (HFA) of the ESC. Eur. Heart J. 2016, 37, 2129-2200. [PubMed]

14. Van Reenen, M.; Janssen, B. EQ-5D-5L User Guide: Basic Information on How to Use the EQ-5D-5L Instrument; EuroQol Research Foundation: Rotterdam, The Netherlands, 2015.

15. National Comprehensive Cancer Network. NCCN Clinical Practice Guidelines in Oncology (NCCN Guidelines $\left.{ }^{\circledR}\right) ;$ Antiemesis, Version 2; National Comprehensive Cancer Network: Pennsylvania, PA, USA, 2016.

16. Chavez-MacGregor, M.; Niu, J.; Zhang, N.; Elting, L.S.; Smith, B.D.; Banchs, J.; Hortobagyi, G.N.; Giordano, S.H. Cardiac monitoring during adjuvant trastuzumab-based chemotherapy among older patients with breast cancer. J. Clin. Oncol. 2015, 33, 2176. [CrossRef] [PubMed]

17. Florido, R.; Smith, K.L.; Cuomo, K.K.; Russell, S.D. Cardiotoxicity from Human Epidermal Growth Factor Receptor-2 (HER 2) Targeted Therapies. J. Am. Heart Assoc. 2017, 6, e006915. [CrossRef] [PubMed]

18. Romond, E.H.; Jeong, J.-H.; Rastogi, P.; Swain, S.M.; Geyer, C.E., Jr.; Ewer, M.S.; Rathi, V.; Fehrenbacher, L.; Brufsky, A.; Azar, C.A. Seven-year follow-up assessment of cardiac function in NSABP B-31, a randomized trial comparing doxorubicin and cyclophosphamide followed by paclitaxel (ACP) with ACP plus trastuzumab as adjuvant therapy for patients with node-positive, human epidermal growth factor receptor 2-positive breast cancer. J. Clin. Oncol. 2012, 30, 3792-3799. [PubMed]

19. Ezaz, G.; Long, J.B.; Gross, C.P.; Chen, J. Risk prediction model for heart failure and cardiomyopathy after adjuvant trastuzumab therapy for breast cancer. J. Am. Heart Assoc. 2014, 3, e000472. [CrossRef] [PubMed]

20. Rushton, M.; Johnson, C.; Dent, S. Trastuzumab-induced cardiotoxicity: Testing a clinical risk score in a real-world cardio-oncology population. Curr. Oncol. 2017, 24, 176-180. [CrossRef]

21. Negishi, K.; Negishi, T.; Hare, J.L.; Haluska, B.A.; Plana, J.C.; Marwick, T.H. Independent and incremental value of deformation indices for prediction of trastuzumab-induced cardiotoxicity. J. Am. Soc. Echocardiogr. 2013, 26, 493-498. [CrossRef] [PubMed]

22. Sawaya, H.; Sebag, I.A.; Plana, J.C.; Januzzi, J.L.; Ky, B.; Cohen, V.; Gosavi, S.; Carver, J.R.; Wiegers, S.E.; Martin, R.P. Early detection and prediction of cardiotoxicity in chemotherapy-treated patients. Am. J. Cardiol. 2011, 107, 1375-1380. [CrossRef] [PubMed]

23. Seferina, S.C.; Maaike de Boer, M.; van den Berkmortel, F.; van Kampen, R.J.; van de Wouw, A.J.; Joore, M.; Peer, P.G.; Voogd, A.C.; Tjan-Heijnen, V.C. Cardiotoxicity and cardiac monitoring during adjuvant trastuzumab in daily Dutch practice: A study of the Southeast Netherlands Breast Cancer Consortium. Oncologist 2016, 21, 555. [CrossRef]

24. Thavendiranathan, P.; Abdel-Qadir, H.; Fischer, H.D.; Liu, Y.; Camacho, X.; Amir, E.; Austin, P.C.; Lee, D.S. Risk-imaging mismatch in cardiac imaging practices for women receiving systemic therapy for early-stage breast cancer: A population-based cohort study. J. Clin. Oncol. 2018, 36, 2980-2987. [CrossRef]

25. Von Minckwitz, G.; Procter, M.; de Azambuja, E.; Zardavas, D.; Benyunes, M.; Viale, G.; Suter, T.; Arahmani, A.; Rouchet, N.; Clark, E. Adjuvant pertuzumab and trastuzumab in early HER2-positive breast cancer. N. Engl. J. Med. 2017, 377, 122-131. [CrossRef] [PubMed] 
26. Arnaout, A.; Zhang, J.; Frank, S.; Momtazi, M.; Cordeiro, E.; Roberts, A.; Ghumman, A.; Fergusson, D.; Stober, C.; Pond, G. A Randomized Controlled Trial Comparing Alloderm-RTU with DermACELL in Immediate Subpectoral Implant-Based Breast Reconstruction. Curr. Oncol. 2021, 28, 184-195. [CrossRef] [PubMed]

27. Awan, A.; Ng, T.; Conter, H.; Raskin, W.; Stober, C.; Simos, D.; Pond, G.; Dhesy-Thind, S.; Mates, M.; Kumar, V.; et al. Feasibility outcomes of a randomised, multicentre, pilot trial comparing standard 6-monthly dosing of adjuvant zoledronate with a single one-time dose in patients with early stage breast cancer. J. Bone Oncol. 2020, 26, 100343. [CrossRef] [PubMed]

28. Clemons, M.; Stober, C.; Kehoe, A.; Bedard, D.; MacDonald, F.; Brunet, M.-C.; Saunders, D.; Vandermeer, L.; Mazzarello, S.; Awan, A. A randomized trial comparing vascular access strategies for patients receiving chemotherapy with trastuzumab for early-stage breast cancer. Supportive Care Cancer 2020, 28, 4891-4899. [CrossRef]

29. Clemons, M.; Fergusson, D.; Simos, D.; Mates, M.; Robinson, A.; Califaretti, N.; Zibdawi, L.; Bahl, M.; Raphael, J.; Ibrahim, M. A multicentre, randomised trial comparing schedules of G-CSF (filgrastim) administration for primary prophylaxis of chemotherapy-induced febrile neutropenia in early stage breast cancer. Ann. Oncol. 2020, 31, 951-957. [CrossRef]

30. Clemons, M.; Ong, M.; Stober, C.; Ernst, S.; Booth, C.; Canil, C.; Mates, M.; Robinson, A.; Blanchette, P.; Joy, A.A. A randomised trial of 4-versus 12-weekly administration of bone-targeted agents in patients with bone metastases from breast or castration-resistant prostate cancer. Eur. J. Cancer 2021, 142, 132-140. [CrossRef] 